\title{
Specialized pediatric palliative care services for children dying from cancer: A repeated cohort study on the developments of symptom management and quality of care over a 10-year period
}

Palliative Medicine 2019, Vol. 33(3) 381-391 (C) The Author(s) 2018 Article reuse guidelines: sagepub.com/journals-permission DOI: $10.1177 / 0269216318818022$ journals.sagepub.com/home/pmj @SAGE

\author{
Boris Zernikow ${ }^{1,2}$ iD, Katharina Szybalski, ${ }^{1,2}$, \\ Bettina Hübner-Möhler ${ }^{1,2}$, Julia Wager ${ }^{1,2}$, Michael Paulussen ${ }^{3}$, \\ Lisa Lassay4, Norbert Jorch ${ }^{5}$, Carola Weber6, Dominik T Schneider7, \\ Gisela Janßen ${ }^{8}$, Prasad T Oommen ${ }^{8}$, Michaela Kuhlen ${ }^{8}$, Thomas Brune9, \\ Regina Wieland ${ }^{10}$, Michael Schündeln ${ }^{10}$, Bernhard Kremens ${ }^{10}$, \\ Alfred Längler ${ }^{11}$, Aram Prokop ${ }^{12}$, Rita Kiener ${ }^{13}$, Tim Niehues ${ }^{14}$, \\ Martina Rose ${ }^{15}$, Margit Baumann-Köhler ${ }^{16}$, Monika Pöppelmann ${ }^{16}$, \\ Heike Thorer ${ }^{16}$, Martin Irnich ${ }^{17}$, Kumar Sinha ${ }^{18}$, Joanne Wolfe ${ }^{19}$ \\ and Pia Schmidt ${ }^{1,2}$
}

\author{
Abstract \\ distressing. \\ pediatric palliative care structures were associated with quality of care.

\footnotetext{
1Paediatric Palliative Care Centre and German Paediatric Pain Centre Children's and Adolescents' Hospital, Datteln, Germany.

2Department of Children's Pain Therapy and Paediatric Palliative Care, School of Medicine, Faculty of Health, Witten/Herdecke University, Datteln, Germany

${ }^{3}$ Children's and Adolescents' Hospital Datteln and Department of Pediatrics, School of Medicine, Faculty of Health, Witten/Herdecke University, Datteln, Germany

${ }^{4}$ University Hospital Aachen, Division of Pediatric Hematology, Oncology and Stem Cell Transplantation, Department of Pediatrics, RWTH Aachen University, Aachen, Germany

${ }^{5}$ Department of Pediatrics, Protestant Hospital Bielefeld, Bielefeld, Germany

${ }^{6}$ Department of Pediatric Oncology, Hematology and Immunology, University Hospital Bonn, Bonn, Germany

${ }^{7}$ Division of Pediatric Hematology and Oncology, Department of Pediatrics, Hospital Dortmund, Dortmund, Germany

${ }^{8}$ Department of Pediatric Oncology, Hematology and Clinical Immunology, Medical Faculty, University Hospital Düsseldorf, Düsseldorf, Germany

${ }^{9}$ Department of Pediatrics, Hospital Lippe-Detmold, Detmold, Germany

${ }^{10}$ Hematology/Oncology, Pediatrics III, University Hospital Essen, Essen, Germany

${ }^{11}$ Gemeinschaftskrankenhaus Herdecke and Integrative Pediatrics, School of Medicine, Faculty of Health, Witten/Herdecke University, Herdecke, Germany
}

Background: About one quarter of children affected with cancer die. For children and their families, the end-of-life period is highly

Aim: This study focused on how end-of-life care in pediatric cancer patients changed over a period of 10 years and if changes in

${ }^{12}$ Department of Pediatric Hematology/Oncology, Children's Hospita Köln, Köln, Germany

${ }^{13}$ Department of Paediatric Oncology and Hematology, Policlinic for Children and Adolescents, University Hospital Köln, Köln, Germany

${ }^{14}$ Centre for Pediatrics and Adolescent Medicine, HELIOS Hospital Krefeld, Krefeld, Germany

${ }^{15}$ Department for Children and Adolescents, Johannes Wesling Hospital Minden, Bochum University, Minden, Germany

${ }^{16}$ Department of Paediatric Hematology and Oncology, Policlinic for Children and Adolescents, University Hospital Münster, Münster, Germany

${ }^{17}$ Department of Paediatric Hematology and Oncology, Asklepios Hospital Sankt Augustin GmbH, Sankt Augustin, Germany

${ }^{18}$ Department of Pediatrics, Helios Medical Centre, Witten-Herdecke University, Wuppertal, Germany

${ }^{19}$ Department of Psychosocial Oncology and Palliative Care, DanaFarber Cancer Institute, Boston Children's Hospital, Harvard Medical School, Boston, MA, USA

Corresponding author:

Boris Zernikow, Paediatric Palliative Care Centre and German Paediatric Pain Centre, Children's and Adolescents' Hospital, Dr.-Friedrich-SteinerStraße 5, 45711 Datteln, Germany.

Email: b.zernikow@kinderklinik-datteln.de 
Design: Over a 10-year period, all pediatric oncology departments in one German federal state were invited to participate in a repeated cross-sectional cohort study at three time-points $(2005,2010,2015)$. Departments invited parents whose children died due to cancer 5 years earlier to participate. Identical semi-structured interviews were conducted with each cohort by the Survey of Caring for Children with Cancer. In addition, departments provided information on their pediatric palliative care infrastructure.

Participants: In total, 124 families participated; $73 \%$ of interviews were conducted with mothers, $18 \%$ with fathers, and $9 \%$ with both parents.

Results: Parents' perception of symptom occurrence, symptom burden, and effectiveness of symptom-related treatment remained stable over the 10 -year period. Over time, the availability of pediatric palliative care $(p<0.001)$ as well as quality and satisfaction ratings of care $(p<0.001)$ increased significantly. A growing number of children received specialized pediatric palliative care at home during the end-of-life period $(p=0.009)$. Along with this development, more families had the chance to plan the location of death $(p=0.003)$, and more children died at the preferred location $(p=0.001)$.

Conclusion: Advances in the availability of pediatric palliative care were associated with improvement in some aspects of quality of care (e.g. location of death) while other aspects, such as effectiveness of symptom management, remained unchanged. Further research is required to determine whether additional improvement in structural quality may increase the effectiveness of symptom management.

\section{Keywords}

Palliative care, palliative medicine, pediatrics, quality of health care, symptom assessment, cancer

\section{What is already known about this topic?}

- High symptom burden and decreased quality of life are regularly experienced during the child's end-of-life period.

- Pediatric palliative home care enables families to have their child with cancer treated at home instead of in the hospital, even during critical stages.

- Children experience better quality of life when they spend the end-of-life period at home.

\section{What this paper adds?}

- Law regulations facilitate specialized pediatric palliative care at home for children with cancer during the end-of-life period.

- A better pediatric palliative care infrastructure is associated with better quality of care and higher parents' satisfaction.

- Improved pediatric palliative care infrastructure allows more children to die in the family's preferred location.

\section{Implications for practice, theory, or policy}

- Pediatric palliative care infrastructure should be strengthened to improve outcomes for children who die due to cancer.

\section{Introduction}

Survival rates of children and adolescents with cancer vary by cancer type. Overall, for about one quarter of children with this disease, cancer or treatment-related complications leads to death. ${ }^{1-4}$ High physical and emotional symptom burden and an increasing impairment in quality of life are regularly experienced by the child during the end-of-life period. ${ }^{5-10}$ Particularly, during the last weeks of life, a rapid increase in highly distressing symptoms can be observed. ${ }^{11}$ Unfortunately, symptom management is often unsatisfying for families. , $7,12-15$ Symptom management is considered successful by parents in less than $50 \%$ of children who suffer from pain and dyspnea; for fatigue, poor appetite, and diarrhea, treatment success rates are below $20 \%$. $^{2,7,14,16}$
In Germany, today, every health-insured citizen (insurance rate in Germany: 99.9\%) who is diagnosed with an incurable disease has the right to receive specialized palliative home care provided by a multi-professional team due to a law passed in 2007. ${ }^{17-19}$ The availability of pediatric palliative home care enables families to have their child treated at home instead of in the hospital, even during critical stages. Multiple studies demonstrate that children experience better quality of life when they spend the end-of-life period at home. ${ }^{13,20,21}$ In order to provide this service, extensive professional support is required. ${ }^{10,17,22-24}$ If specialized home care with a $24 / 7$ on-call service cannot be guaranteed, many children with cancer die in hospitals, often within clinically focused intensive care units. $2,7,25-27$

Due to these conflicting outcomes, the current study examines how end-of-life care in pediatric cancer patients, 
parent-reported symptom burden of the child, and parents' satisfaction with treatment have changed over a 10-year period, from 2000 to 2010 . We hypothesized that quality of care for all patients has increased over time, due to the aforementioned changes to the law during this time period, as well as the increased availability of pediatric palliative home care teams that have been established. We also hypothesized that children receiving specialized pediatric palliative home care spend more time at home and less time in hospitals during the end-of-life period.

\section{Methods}

\section{Study design}

Between 2005 and 2015, a repeated cross-sectional cohort study has been conducted at three time-points (2005, $2010,2015)$. The study comprises three cohorts assessed with the same study design. At each time-point, all pediatric oncology departments in one German federal state were invited to participate. In 2005, six pediatric oncology departments participated; in 2010, 16 departments participated; and in 2015, 13 departments participated. Two data sources were used: (1) quantitative data from parents collected in a semi-structured interview with the Survey of Caring for Children with Cancer ${ }^{2}$ and (2) structural information on pediatric palliative care provided by the participating pediatric oncology departments.

\section{Data collection}

To gain contact with parents for a semi-structured interview, the participating pediatric oncology departments were asked to send an invitation letter to all families whose children died due to cancer in 1999-2000 (Cohort2000), 2005-2006 (Cohort2005), or 2010-2011 (Cohort2010), respectively. Upon receipt of signed consent, the study coordinator contacted parents by phone and arranged interviews. Parents could choose to be interviewed in person (at home or at a neutral place) or via telephone. Interviews were conducted by trained interviewers, who had not been involved in the child's treatment. Prior to data collection, interviewers were trained in interview techniques and investigation instruments. Interviews were conducted in 2005/2006, 2010/2011, and 2015/2016, respectively.

The structural information of the pediatric oncology departments was assessed with a questionnaire completed by the departments and was available for the years 2005 and 2010.27

\section{Assessment instrument}

A semi-structured interview was conducted with parents using the validated German version ${ }^{13}$ of the Survey of
Caring for Children with Cancer developed by Wolfe and colleagues. ${ }^{2}$ The survey is a comprehensive, semi-structured interview guideline for the assessment of symptoms, quality of life, care delivery, quality of care, and burden after child's death as perceived by the parents. All questions reported in this analysis are closed-ended questions or Likert-type response options.

The structural questionnaire ascertains information about the pediatric oncology departments during the past year and describes the pediatric palliative home care structures of the department. For this study, the questions regarding the availability of 24-h on-call service and the availability of a 24-h outreach pediatric palliative care team were analyzed.

\section{Ethical approval}

Ethical approval was obtained from the ethics committee of the Witten/Herdecke University for each cohort (ID: 04/02; ID: 25/10; ID: 126/2015).

\section{Data analyses}

All data analyses were implemented using SPSS $^{\oplus}$ software (release 25.0). Descriptive statistics are reported as means (M) and standard deviations (SD) or frequencies $(n)$ and percentages (\%).

First, the three cohorts were compared regarding the prevalence of symptoms and perceived symptom burden during the end-of-life period. Different quality aspects were then compared between cohorts: the treatment provided, effectiveness of treatment, availability of psychosocial support, psychosocial care of siblings, and the availability of a physician. In addition, a global rating of quality of care and satisfaction with care was obtained. The effectiveness of symptom management was rated either "not successful," "fairly successful," or "successful." For analyses, "not successful" and "fairly successful" (together: "not successful") were compared to "successful." For ordinal data, a KruskalWallis test (Mann-Whitney test for post hoc comparisons) was performed. For nominal data, $\chi^{2}$ test/Fisher's exact tests were conducted. For all analyses, post hoc comparisons were corrected by means of the BonferroniHolm method.

To assess the effect of the availability of specialized pediatric palliative home care on the quality of care, the group receiving specialized pediatric palliative home care was compared to those who did not. For this study, specialized pediatric palliative home care has been defined as palliative home care provided by a physician and a nurse. Analyses focused on the place of death and utilization of care offers in the end-of-life period. Again, a $\chi^{2}$ test or Kruskal-Wallis test was performed. 


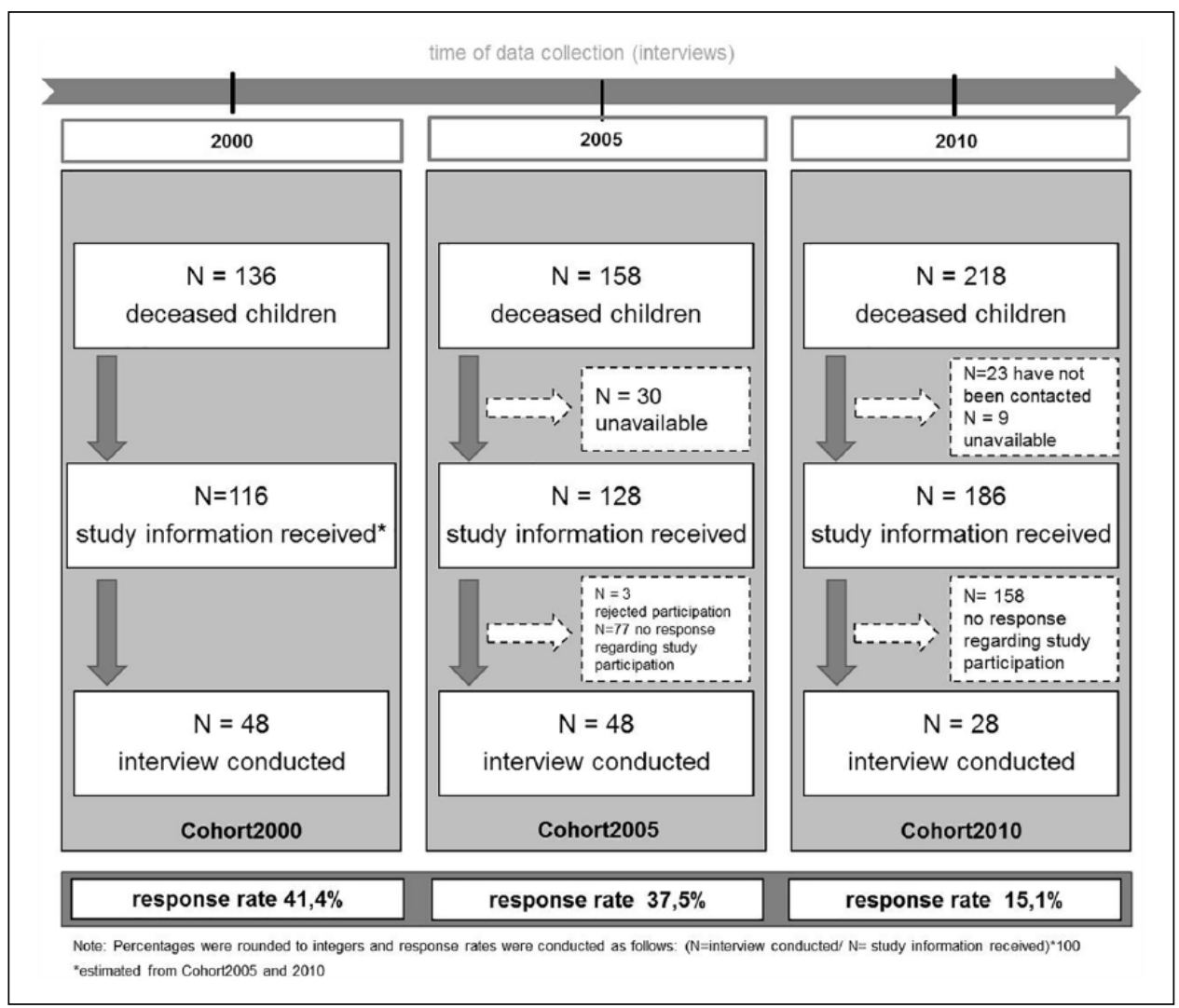

Figure 1. Response rates for the cohorts, 2000-2010.

\section{Results}

\section{Sample}

Within the three cohorts, 124 interviews were conducted. Figure 1 provides an overview of response rate within each cohort. Cohort2000 and Cohort2005 each consisted of 48 participants and Cohort2010 consisted of 28 participants.

Overall, $73 \%$ of interviews were conducted with mothers, $18 \%$ were fathers, and $9 \%$ of interviews were conducted with both parents. Most parents (84\%) were married at the time their child died, approximately $12 \%$ were divorced or lived separately, and $3 \%$ were widowed. Face-to-face interviews at home were conducted with $77 \%(n=95)$ of parents, $7 \%(n=9)$ were interviewed faceto-face at another location of their choice, and $16 \%$ ( $n=20)$ participated via a telephone interview.

Table 1 provides information on the characteristics of the sample. Children in the three cohorts did not significantly differ regarding type of cancer and cancer-directed treatment.

\section{Symptoms}

Parents reported their child's symptoms during the endof-life period. For all children, several symptoms were reported (see Figure 2); on average, children experienced 4.4 of the seven queried symptoms (SD =1.6). The most common symptom in all cohorts was fatigue (89\%-92\%), followed by pain $(71 \%-85 \%)$. The rate of symptom occurrence during the end-of-life period did not differ between the three cohorts ( $\chi^{2}$ test; all $p \geqslant 0.082$ ).

Parents were additionally asked to assess whether the symptoms were distressing for their child. Figure 2 displays the percentage of symptoms perceived as distressing. Dyspnea (59\%-80\%) and pain $(46 \%-75 \%)$ were the most frequent distressing symptoms. Lessened appetite was the least reported distressing symptom (24\%-39\%). The number of symptoms perceived as distressing did not differ between cohorts ( $\chi^{2}$ test; all $p \geqslant 0.029$; not significant after the Bonferroni-Holm correction). For fatigue, there was a tendency for a higher number of parents to report the symptom as distressing in the most recent cohort (Cohort2010) $\left(\chi^{2}(2)=7.738, p=0.020\right.$; not significant after the Bonferroni-Holm correction).

\section{Treatment of symptoms}

Parents also reported if children received treatment for the existing symptoms (Figure 3). Across cohorts, pain (95\%-100\%) was the most often treated symptom followed by nausea (73\%-100\%) and dyspnea (72\%-80\%). 
Table 1. Characteristics of children who died of cancer $(N=124)$.

\begin{tabular}{|c|c|c|c|c|c|c|}
\hline & All cohorts $(n=124)$ & Cohort2000 $(n=48)$ & Cohort2005 $(n=48)$ & Cohort2010 $(n=28)$ & Test statistics & $p$-values \\
\hline & $M \pm S D$ & $M \pm S D$ & $M \pm S D$ & $M \pm S D$ & $\begin{array}{l}\text { Kruskal-Wallis } \\
\text { test }\end{array}$ & \\
\hline Age at diagnosis & $7.2 \pm 5.7$ & $6.0 \pm 4.5$ & $7.2 \pm 6.8$ & $9.5 \pm 4.9$ & 8.239 & $0.016^{a}$ \\
\hline \multirow[t]{2}{*}{ Age at death } & $9.9 \pm 6.3$ & $8.3 \pm 4.9$ & $9.9 \pm 7.3$ & $12.4 \pm 6.0$ & 8.488 & $0.014^{a}$ \\
\hline & $n(\%)$ & $n(\%)$ & $n(\%)$ & n (\%) & $\chi^{2}$ test & \\
\hline Sex (male) & $89(71.8)$ & $31(64.6)$ & $37(77.1)$ & $21(75.0)$ & 2.037 & 0.361 \\
\hline \multicolumn{7}{|l|}{ Type of cancerb } \\
\hline Leukemia & $28(22.6)$ & $14(29.2)$ & $10(20.8)$ & $4(14.3)$ & 2.377 & 0.305 \\
\hline Brain tumor & $38(30.6)$ & $10(20.8)$ & $19(39.6)$ & $9(32.1)$ & 4.008 & 0.135 \\
\hline Neuroblastoma & $14(11.3)$ & 9 (18.8) & $3(6.3)$ & $2(7.1)$ & 4.365 & 0.113 \\
\hline Sarcoma & $17(13.7)$ & $6(12.5)$ & $8(16.7)$ & $3(10.7)$ & 0.627 & 0.731 \\
\hline Other tumors & $33(26.6)$ & $9(18.8)$ & $14(29.2)$ & $10(35.7)$ & 2.867 & 0.272 \\
\hline \multicolumn{7}{|c|}{ Cancer directed treatment } \\
\hline After diagnosis & $121(98.4)$ & $47(100)$ & $48(100)$ & 26 (92.9) & $4.330^{c}$ & 0.050 \\
\hline At end-of-life & $53(43.4)$ & $20(42.6)$ & $21(43.8)$ & $12(44.4)$ & 0.028 & 0.986 \\
\hline
\end{tabular}

aFor each segment of the table, the results were corrected by the Bonferroni-Holm method; indicates significant results. bIn some children, multiple cancer types were reported.

'Fisher's exact test.

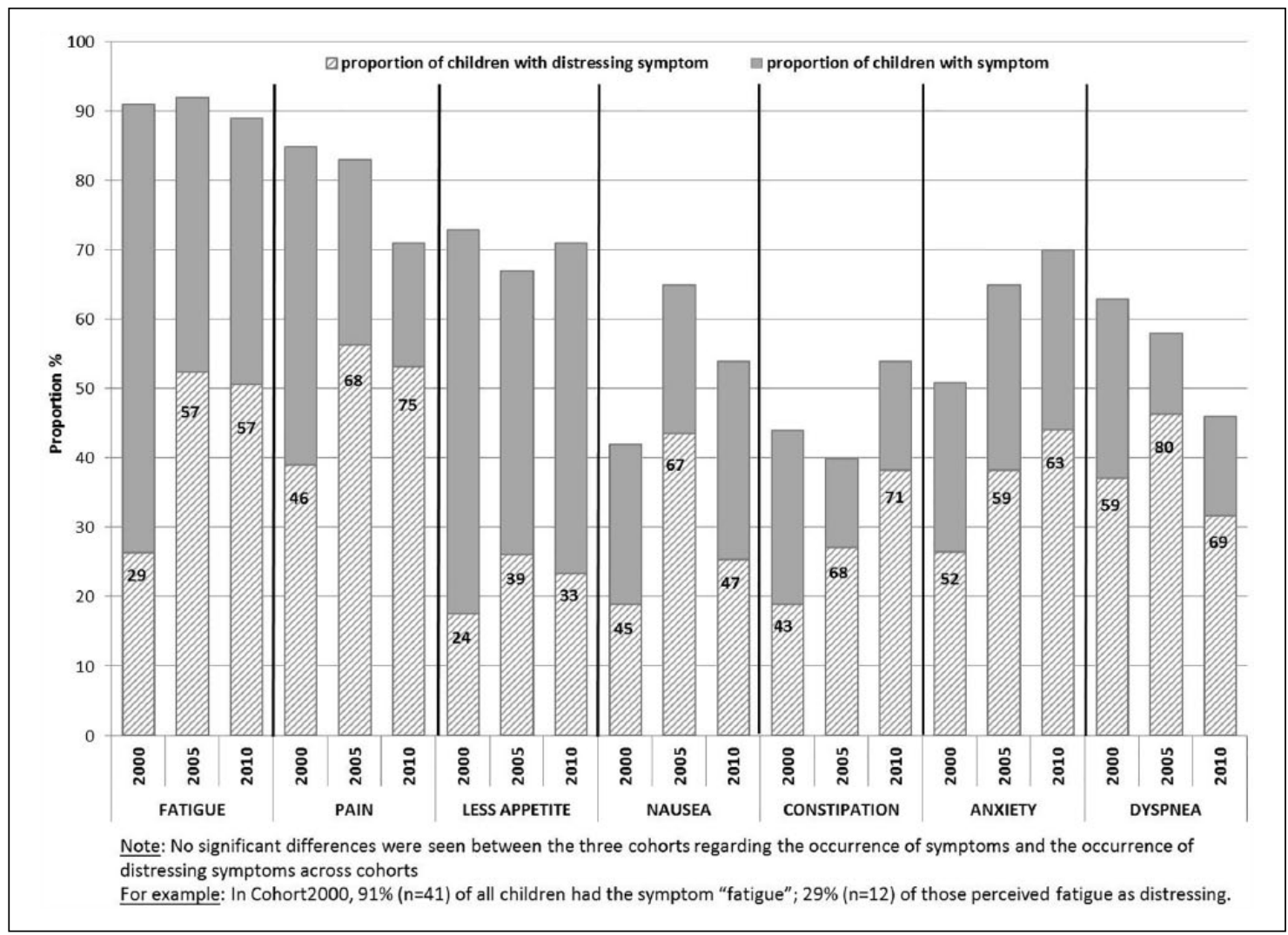

Figure 2. Occurrence of symptoms across the three cohorts and the level of distress.

Anxiety was only treated in $11 \%-47 \%$ of the children experiencing this symptom. Fatigue was treated in $3 \%-$ $19 \%$ of cases, low appetite in $37 \%-47 \%$ of cases, and constipation in $5 \%-93 \%$ of cases. Across cohorts, a significant increase for receiving treatment of constipation $\left(\chi^{2}(2)=43.195, p<0.001\right)$ and anxiety $\left(\chi^{2}(2)=6.284\right.$, 


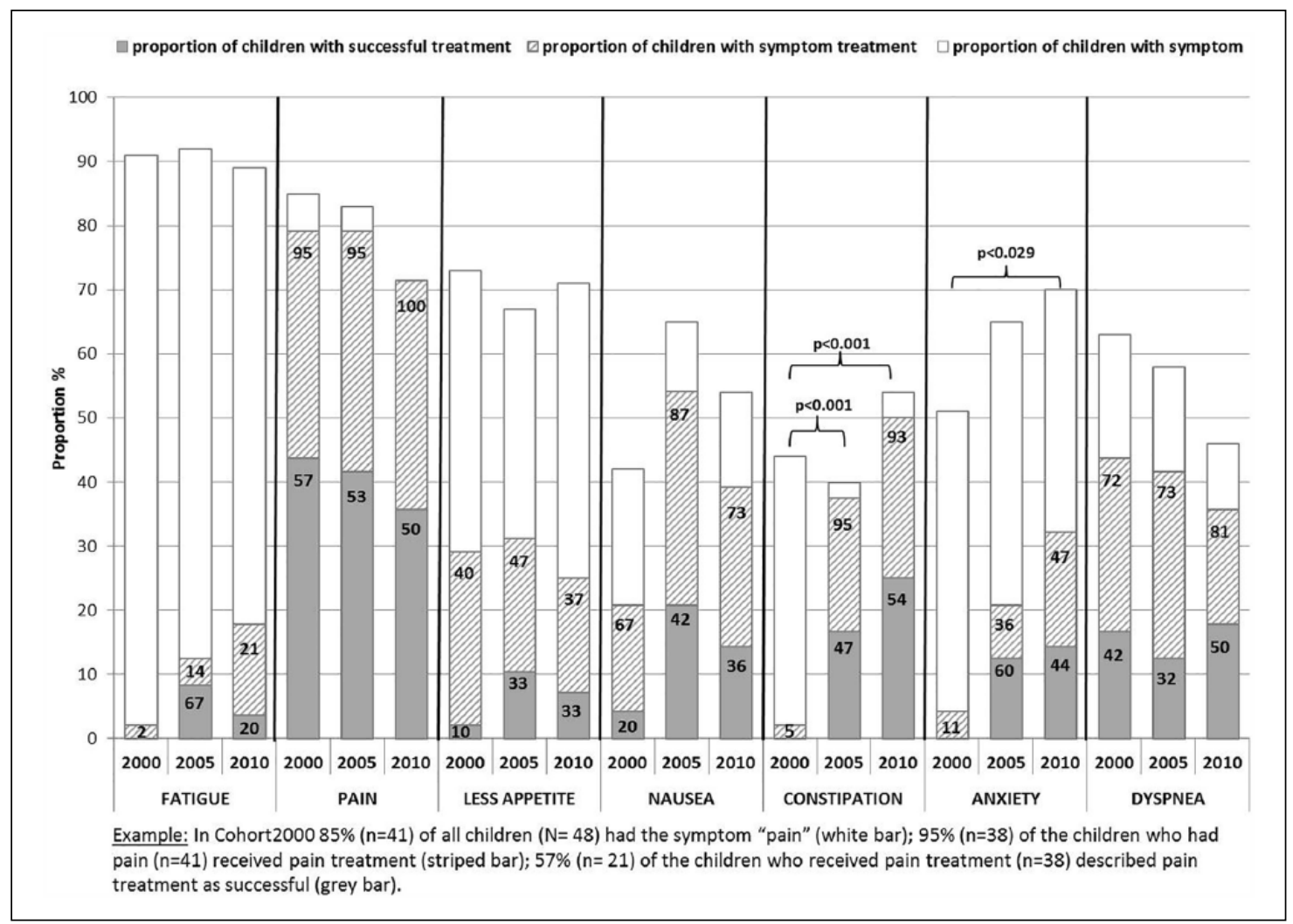

Figure 3. Treatment of symptoms across the three cohorts and its effectiveness.

$p=0.044)$ was observed. Post hoc analyses for constipation showed a significant increase from Cohort2000 to Cohort2005 $\left(\chi^{2}(1)=32.382, \quad p<0.001\right)$ and from Cohort2000 to Cohort2010 $\left(\chi^{2}(1)=28.242, p<0.001\right)$. Post hoc analysis for anxiety showed a significant increase from Cohort2000 to Cohort2010 $\left(X^{2}(1)=6.269\right.$, $p=0.029$ ).

Parents were also asked to rate the effectiveness of treatment their child received (Figure 3). Analyses demonstrated treatment was successful in $53 \%-57 \%$ of cases for the treatment of pain, followed by treatment of dyspnea $(32 \%-50 \%)$ and treatment of constipation (47\%$54 \%)$. In cohort comparisons, the success of symptom management did not differ for any symptom ( $\chi^{2}$ tests; all $p \geqslant 0.242$ ).

\section{Characteristics of care}

Parents were asked to provide information on the characteristics of care during the end-of-life period of their child. The number of families receiving psychosocial support during end-of-life care did not differ across cohorts (Cohort2000: 45.8\%; Cohort2005: 56.3\%; Cohort2010: $\left.32.1 \% ; \chi^{2}(2)=4.156, p=0.143\right)$. In addition, the psychosocial care of siblings did not change over time (Cohort2000: 29.4\%; Cohort2005: 18.8\%; Cohort2010: $\left.16.7 \% ; \chi^{2}(2)=1.030, p=0.681\right)$.
However, across cohorts, a significant increase was present in the availability of a treating physician during daytime (Kruskal-Wallis test; $\chi^{2}(2)=61.30, p<0.001$ ) and during the weekends and at night (Kruskal-Wallis test; $\chi^{2}(2)=41.849, p<0.001$ ). Post hoc tests revealed a significant increase in the daytime availability of a physician in the palliative care situation from Cohort2000 to Cohort2010 $(p<0.001)$ and from Cohort2005 to Cohort2010 $(p<0.001)$. Specifically, in Cohort2000 and Cohort2005, a physician was rated as available for the family "most of the time" in only $4 \%$ of cases, which increased to $93 \%$ in Cohort2010. In addition, a significant increase was present in availability of physicians at night and on weekends from Cohort2000 to Cohort2010 $(p<0.001)$ and from Cohort2005 to Cohort2010 $(p<0.001)$. In Cohort2000, 17\% of families reported a physician was available "most of the time" at night and during weekends, compared to $11 \%$ of families in Cohort2005. Differentially, physicians were rated as "always" available by $91 \%$ of families in Cohort2010 (Figure 4).

\section{Appraisal of the quality of palliative home care}

In Cohort2000, 34.8\% received specialized pediatric palliative home care, with the proportion increasing to 


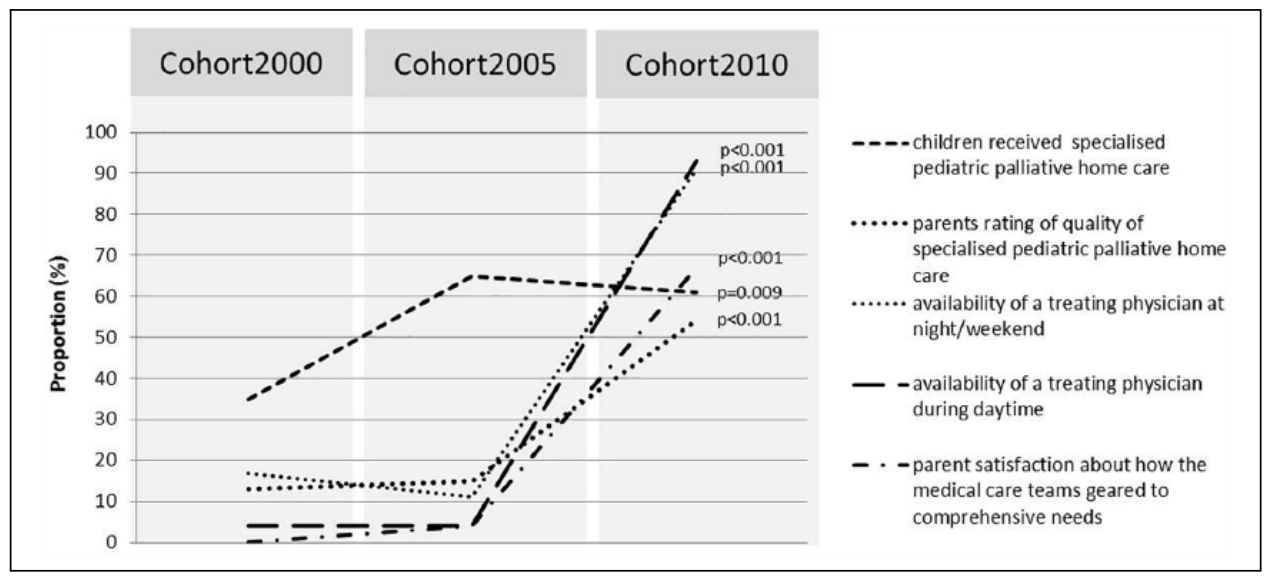

Figure 4. Quality of home care over the three cohorts.

$64.6 \%$ in Cohort2005 and 60.7\% in Cohort2010 $\left(\chi^{2}(2)=9.357, p=0.009\right)$. Post hoc tests revealed significant differences between Cohort2000 and Cohort2005 $(p=0.004)$ and between Cohort2000 and Cohort2010 $(p=0.030)$ (Figure 4).

In those who received specialized pediatric palliative home care, parents rated the quality of care during their child's end-of-life period. An overall rating of quality showed a significant increase in satisfaction between earlier and later cohorts (Kruskal-Wallis test; $\left.\chi^{2}(2)=15.995, p<0.001\right)$. The post hoc comparison revealed a significant increase in the parent's quality rating when comparing earlier cohorts to Cohort 2010 (Mann-Whitney test; Cohort2000/Cohort 2005: $p=0.492$; Cohort2000/Cohort2010: $p=0.002$; Cohort2005/Cohort2010: $p<0.001$ ) (Figure 4). Cohorts further differed regarding the rating of satisfaction of how the medical care teams tailored their care to the comprehensive needs of the children at home (Kruskal-Wallis test; $\chi^{2}(2)=19.623, p<0.001$ ). Pairwise post hoc comparisons showed the same pattern, in which Cohort2010 had significantly higher ratings than earlier cohorts (Mann-Whitney test; Cohort2000/Cohort2005: $\quad p=0.983$; Cohort2000/ Cohort2010: $\quad p=0.001$; Cohort2005/Cohort2010: $p<0.001$ ) (Figure 4).

\section{Effects of the involvement of specialized pediatric palliative home care on quality}

Consistent with information provided by parents, analyses of the structural data provided by the oncology departments demonstrated a shift in the availability of specialized pediatric palliative home care teams. In 2005, $67 \%$ of departments had employees who were available $24 \mathrm{~h} / 7$ days for patients receiving home care compared to $80 \%$ in 2010 . Outreach on call was only offered by $21 \%$ of departments in 2005 compared to $71 \%$ of departments in 2010.
Families of children receiving specialized pediatric palliative home care reported more often that they were able to plan the location of death for their child $(74.6 \%$ vs 48.3\%; $\left.\chi^{2}(1)=8.883, p=0.003\right)$. Families with specialized pediatric palliative home care also reported more often that their child died at the place they had planned $(92.0 \%$ vs $\left.64.3 \% ; \chi^{2}(1)=10.669, p=0.001\right)$. Most children receiving specialized pediatric palliative home care died at home (78.1\%) compared to the children without specialized pediatric palliative home care $(19.0 \%)\left(\chi^{2}(1)=42.595\right.$, $p<0.001$ ) (Figure 5).

The number of hospital stays were also lower during the end-of-life period for children who received specialized pediatric palliative home care (Mann-Whitney test: $Z=-6.353, p<0.001)$. Of the children receiving specialized pediatric palliative home care, $60.3 \%$ did not stay in the hospital during their last month of life compared to those without specialized pediatric palliative home care in which only $15.5 \%$ did not spend time in the hospital (Figure 5). Regarding the days spent in a hospice or the utilization of outpatient treatment or daycare, no difference occurred between those with or without specialized pediatric palliative home care (Mann-Whitney tests; all $p \geqslant 0.723$ ).

\section{Discussion}

Availability of specialized pediatric palliative home care has increased over time. We found evidence of increased availability in terms of number of teams providing this service, as well as increased option of outreach support. Advances in pediatric palliative care structure and availability were associated with an improvement in some aspects of quality of care (e.g. location of death) while other aspects, such as effectiveness of treatment, remained unchanged. Despite parents reporting a similar symptom burden, symptom management, and effectiveness of treatment across cohorts, parents' quality ratings of care increased significantly. Importantly, families 


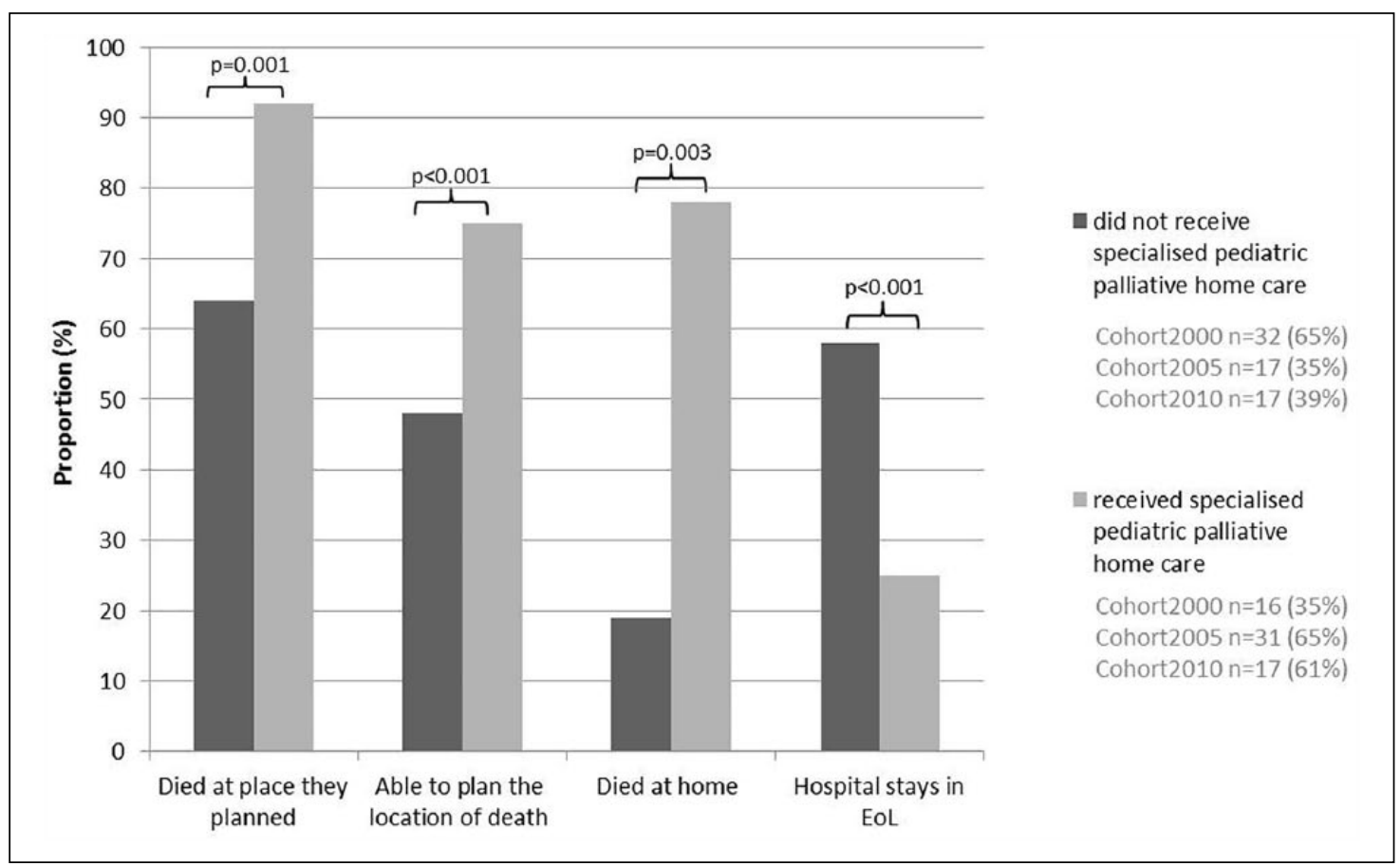

Figure 5. Effects of the involvement of specialized pediatric palliative home care.

receiving specialized pediatric palliative home care were able to plan the location of death more often, their child had fewer hospital stays during the end-of-life period, and their child died at the place planned in advance more frequently. It remains to be determined whether further improvement of other structural factors could additionally increase outcome quality.

Pediatric oncology departments first established palliative home care services in the 1990s, developing specialized programs for their patients. ${ }^{28}$ Once the aforementioned palliative home care law came into practice in $2007,{ }^{17-19}$ these services became accredited. Specialized pediatric palliative home care has three major goals: (1) to achieve and preserve the best quality of life for the patient, (2) to support the entire family, and (3) to facilitate dying in the place of choice. These goals imply effective treatment of stressful symptoms, the provision of relief services as well as medical, nursing, and psychosocial care until death, and support for the family beyond the child's death during the subsequent mourning period.

In our study, frequency of treatment remained stable over time for most symptoms. However, an increase was observed in the treatment of anxiety and constipation. Anxiety not only impairs the child's and the families' quality of life but may also lead to an increase in other symptoms. ${ }^{29}$ Therefore, it is important to treat anxiety consistently. Regarding constipation, treatment benefits, possible adverse events, and symptom burden need to be well balanced. Intensive treatment of constipation is seldom warranted in the last days of life.
Contrary to our expectations, the effectiveness of treatment did not increase over time despite better availability of specialized pediatric palliative home care. There are several possible explanations for this finding: (1) the effectiveness of treatment in children dying of cancer is naturally limited and cannot further be increased even while offering the best pediatric palliative care possible (ceiling effect), (2) the quality of pediatric palliative care is still not sufficient and has to be increased by further training, (3) the treatment effectiveness may have increased, but at the same time the expectations toward treatment effectiveness may have also increased and the willingness to accept symptoms at the end of life may have decreased, resulting in an unchanged judgment of effectiveness.

The current findings also showed that the number of families and siblings receiving psychosocial support remained stable at a low level over the 10-year study period. Psychological support is an important aspect of structural quality and is of utmost importance for the whole family. ${ }^{29,30}$ In particular, siblings are at high risk for psychological distress and risky behaviors ${ }^{31}$ within 1 year after their sibling has been diagnosed with cancer. ${ }^{32-34}$ Thus, there remains room for further improvement concerning psychological support for children and their families during the end-of-life period. This could be addressed if contemporaneous psychosocial care was remunerated in the law on palliative home care in Germany.

Another essential quality aspect in the end-of-life period for children and their families is facilitating death 
at the place of choice. Comparable to international studies, ${ }^{24,35}$ our study revealed that families of children receiving specialized pediatric palliative home care reported that they were able to plan the location of death for their child and in most cases, their child died in the place they had chosen. In addition, children receiving specialized pediatric palliative home care died at home much more often compared to children not receiving this service, consistent with other international findings. ${ }^{21,36,37}$ Nevertheless, for some families, inpatient end-of-life care is right for the family. ${ }^{38}$ Thus, it is important to provide flexible care settings with high-quality palliative care options that take the particular needs of the child and family into account. ${ }^{37,39}$

One important aspect of these flexible care settings appears to be a 24/7 on-call service. As the results of our study show, 24/7 on-call availability of a physician during the end-of-life phase increased significantly over the 10 -year period and was reported by $93 \%$ of parents in Cohort2010. Regarding inpatient care, studies reveal that parents, oncologists, and children believe that symptoms such as pain can be better controlled given $24 / 7$ on-call availability. ${ }^{21}$ The same positive effect of $24 / 7$ on-call availability may be observed when children are cared for through a specialized pediatric palliative home care service. For example, parents have reported that on-call availability in specialized pediatric palliative home care improves communication, and they are more satisfied with care. ${ }^{40}$ The increase of $24 / 7$ on-call availability might be one reason that parent satisfaction with care and the overall rating of quality increased over time despite the fact that the degree of symptom control remained stable over the years. ${ }^{41}$

Further explanation for the improvement of parents' rating of quality of care in the end-of-life period may be the lower number of hospital stays in the end-of-life period. More hospital admissions during the end-of-life period have been associated with distress in fathers of childhood cancer patients ${ }^{42}$ and a higher risk of poor adjustment in siblings. ${ }^{43}$ In addition, Ito et al. ${ }^{44}$ reported that it is essential to provide terminally ill pediatric cancer patients with a healthy social environment in addition to providing general and optimal palliative care focusing on patients' physical and psychological distress.

\section{Strength/limitations}

This is the first study describing the long-term development of pediatric palliative care in children dying from cancer in a distinct area. The strength of the study is the sequential study design. Across all three cohorts, a consistent procedure was applied with the same assessment instruments used, within a specified area of Germany. This design allows comparisons across independent cohorts to portray specialized pediatric palliative home care development and associated changes in treatment and treatment success.

The study also has some limitations that need to be considered when interpreting results. First, retrospective interviews were conducted, which bears the risk for recall bias. In the 5 years since the child's death, the parents' memories may have become less clear or distorted. Some researchers have reported that distressing symptoms may be overestimated in retrospective studies. ${ }^{45,46}$ Second, the response rate was rather low. This may be related to the study procedure, in which families were not contacted directly by the research team but by the oncology departments, and they only received one invitation to participate in the study. A second reminder may have improved the participation rate but was not used due to ethical considerations. Third, the participation rate was especially low in the most recent cohort. Even though the three cohorts were statistically comparable and only differed regarding child age, a systematic effect causing the low response rate cannot be eliminated. Interestingly, we found studies in which the permanent decline of survey responses is described for industrial countries since 1900 and across different domains. ${ }^{47,48} \mathrm{~A}$ change in lifestyle and an increasing number of migrants to the area who do not have sufficient German language skills may be another explanation for the decrease in response rates.

\section{What this study adds}

The results of this study indicate that advances in the structure and availability of pediatric palliative care were associated with the improvement of some aspects of quality of care (e.g. location of death) while other aspects, such as effectiveness of treatment, remained unchanged. Concurrently, the study provides important information for improvement of specialized pediatric palliative home care options.

\section{Acknowledgements}

The authors would like to thank the study participants and the German Children's Cancer Fund, which supported the survey.

\section{Declaration of conflicting interests}

The author(s) declared no potential conflicts of interest with respect to the research, authorship, and/or publication of this article.

\section{Funding}

The author(s) disclosed receipt of the following financial support for the research of this article: The study was funded by the German Childhood Cancer Foundation.

\section{ORCID iD}

Boris Zernikow (iD) https://orcid.org/0000-0001-5875-3775 


\section{References}

1. Hurwitz CA, Duncan J and Wolfe J. Caring for the child with cancer at the close of life. JAMA 2004; 292(17): 2141-2149.

2. Wolfe J, Grier HE, Klar N, et al. Symptoms and suffering at the end of life in children with cancer. N Engl J Med 2000; 342(5): 326-333.

3. Kaatsch P, Grabow D and Spix C. German childhood cancer registry (1980-2015). Annual report, Institute of Medical Biostatistics, Epidemiology and Informatics (IMBEI), Johannes Gutenberg University Mainz, Mainz, 2016.

4. Miller KD, Siegel RL, Lin CC, et al. Cancer treatment and survivorship statistics, 2016. CA Cancer J Clin 2016; 66(4): 271-289.

5. Rosenberg AR, Orellana L, Ullrich C, et al. Quality of life in children with advanced cancer: a report from the PediQUEST study. J Pain Symptom Manage 2016; 52(2): 243-253.

6. Wolfe J, Orellana L, Ullrich C, et al. Symptoms and distress in children with advanced cancer: prospective patientreported outcomes from the PediQUEST study. J Clin Oncol 2015; 33(17): 1928-1935.

7. Heath JA, Clarke NE, Donath SM, et al. Symptoms and suffering at the end of life in children with cancer: an Australian perspective. Med J Aust 2010; 192(2): 71-75.

8. Kuhlen $M$, Hoell J, Balzer $S$, et al. Symptoms and management of pediatric patients with incurable brain tumors in palliative home care. Eur J Paediatr Neurol 2016; 20(2): 261-269.

9. Schmidt $\mathrm{P}$, Otto $\mathrm{M}$, Hechler $\mathrm{T}$, et al. Did increased availability of paediatric palliative care lead to improved palliative care outcomes in children with cancer? J Palliat Med 2013; 16: 1034-1039.

10. Von Lutzau $P$, Otto $M$, Hechler $T$, et al. Children dying from cancer: parents perspectives on symptoms, quality of life, characteristics of death and end-of-life decisions. J Palliat Care 2012; 28(4): 274-281.

11. Goldman A, Hain R and Liben S. Oxford textbook of palliative care for children. Oxford: Oxford University Press, 2012.

12. Pritchard M, Burghen EA, Gattuso JS, et al. Factors that distinguish symptoms of most concern to parents from other symptoms of dying children. J Pain Symptom Manage 2010; 39(4): 627-636.

13. Hechler T, Blankenburg M, Friedrichsdorf $\mathrm{S}$, et al. Parents' perspective on symptoms, quality of life, characteristics of death and end-of-life decisions for children dying from cancer. Klin Padiatr 2008; 220(3): 166-174.

14. Theunissen JM, Hoogerbrugge PM, Van Achterberg T, et al. Symptoms in the palliative phase of children with cancer. Pediatr Blood Cancer 2007; 49(2): 160-165.

15. Ullrich C, Dussel V, Hilden JM, et al. Fatigue in children with cancer at the end of life. J Pain Symptom Manage 2010; 40(4): 483-494.

16. Saad R, Huijer HAS, Noureddine $S$, et al. Bereaved parental evaluation of the quality of a palliative care program in Lebanon. Pediatr Blood Cancer 2011; 57(2): 310-316.

17. Craig F, Abu-Saad HH, Benini F, et al. IMPaCCT: standards pädiatrischer Palliativversorgung in Europa. Z Palliativmed 2008; 9: 61-66.
18. Gemeinsamer Bundesausschuss. Richtlinie des Gemeinsamen Bundesausschusses zur Verordnung von spezialisierter ambulanter Palliativversorgung (Spezialisierte Ambulante Palliativversorgungs-Richtlinie / SAPV-RL). Berlin, Bundesanzeiger des Gemeinsamen Bundesausschuss, 2008, p. 911.

19. Beck CH. German social law order book v-public health sector. Munich, Deutscher Taschenbuchverlag, 2010.

20. Craft A and Killen S. Palliative care services for children and young people in England: an independent review for the secretary of state for health. London: Department of Health, 2007.

21. Friedrichsdorf SJ, Postier A, Dreyfus J, et al. Improved quality of life at end of life related to home-based palliative care in children with cancer. J Palliat Med 2015; 18(2): 143-150.

22. Vickers J, Thompson A, Collins GS, et al. Place and provision of palliative care for children with progressive cancer: a study by the paediatric oncology Nurses' forum/United Kingdom children's cancer study group palliative care working group. J Clin Oncol 2007; 25(28): 4472-4476.

23. Papadatou D, Yfantopoulos J and Kosmidis HV. Death of a child at home or in hospital: experiences of Greek mothers. Death Stud 1996; 20(3): 215-235.

24. Kassam A, Skiadaresis J, Alexander S, et al. Parent and clinician preferences for location of End-of-Life care: home, hospital or freestanding hospice? Pediatr Blood Cancer 2013; 61: 859-854.

25. Drake R, Frost J and Collins JJ. The symptoms of dying children. J Pain Symptom Manage 2003; 26(1): 594-603.

26. Yanai T, Hirase S, Matsunoshita N, et al. Place of death of pediatric cancer patients in a single institute during 7 years. Kobe J Med Sci 2012; 58(2): E33-E40.

27. Von Lützau $P$ and Zernikow B. [Pediatric palliative care service provided by Paediatric Oncology Departments in North Rhine-Westphalia, Germany]. Z Palliativmed 2013; 14: $114-120$.

28. Zernikow B, Michel E and Garske D. [Palliative care basicsstructural and organizational basics]. In: Zernikow B (ed.) Palliative care for children, adolescents and young adults. 2nd ed. Berlin: Springer, 2013, p. 3-36.

29. Führer M. Kinderpalliativmedizin. Monatsschrift Kinderheilkunde 2011; 159: 583-596.

30. Herold R, Reiche R, Creutzig U, et al. Stand und Bewertung der Strukturen und Ausstattung pädiatrisch-onkologischhämatologischer Kliniken. Klin Padiatr 2007; 219: 390.

31. Rosenberg AR, Postier A, Osenga $K$, et al. Long-term psychosocial outcomes among bereaved siblings of children with cancer. J Pain Symptom Manage 2015; 49(5): 55-65.

32. Binger C. Childhood leukemia: emotional impact on siblings. In: Anthony EJ and Koupernik C (eds) The child and his family: the impact of disease and death, vol. 2. New York: John Wiley \& Sons, 1973, pp. 195-209.

33. Powazek M, Payne JS, Goff J, et al. Psychosocial ramifications of childhood leukemia: one year post-diagnosis. In: Shulman JL and Kupst MJ (eds) The child with cancer. New York: Springer, 1980, pp. 143-155.

34. Avison W, Noh S and Speechley K. Parents as caregivers: caring for children with health problems. Adv Med Sociol 1991; 2: 65-94. 
35. Rusalen F, Agosto C, Brugnaro L, et al. Impact of the regional pediatric palliative care network on the care of children on long-term ventilation: could the availability of a residential solution into the network reduce the duration of intensive care unit staying for these patients? J Pediatr Intensive Care 2018; 7: 75-80.

36. Gans D, Kominski GF, Roby DH, et al. Better outcomes, lower costs: palliative care program reduces stress, costs of care for children with life-threatening conditions. Policy Brief UCLA Cent Health Policy Res 2012; PB2012-3: 1-8.

37. Fraser LK, Fleming $S$ and Parslow R. Changing place of death in children who died after discharge from paediatric intensive care units: a national, data linkage study. Palliat Med 2018; 32(2): 337-346.

38. Zernikow B and Frühwald M. [Specifics of paediatric palliative care in specific patients (7.5 paediatric oncology)]. In: Zernikow B (ed.) Palliative care for children, adolescents and grownups. Heidelberg: Springer, 2013, pp. 377-483.

39. Jünger $S$, Pastrana $T$, Pestinger $M$, et al. Barriers and needs in paediatric palliative home care in Germany: a qualitative interview study with professional experts. BMC Palliat Care 2010; 9: 10.

40. Kremeike K, Mohr A, Nachtmann J, et al. Evaluation der spezialisierten ambulanten pädiatrischen Palliativversorgung in Niedersachsen-Eine qualitative Studie zur Elternsicht. Das Gesundheitswesen 2016; 78: 306-312.
41. Howard M, Goertzen J, Hutchison B, et al. Patient satisfaction with care for urgent health problems: a survey of family practice patients. Ann Fam Med 2007; 5(5): 419-424.

42. Sloper P. Predictors of distress in parents of children with cancer: a prospective study. J Pediatr Psychol 2000; 25(2): 79-91.

43. Sloper P and While D. Risk factors in the adjustment of siblings of children with cancer. J Child Psychol Psychiatry 1996; 37(5): 597-607.

44. Ito $Y$, Okuyama $T$, Ito $Y$, et al. Good death for children with cancer: a qualitative study. Jpn J Clin Oncol 2015; 45(4): 349-355.

45. Broderick JE, Schwartz JE, Vikingstad G, et al. The accuracy of pain and fatigue items across different reporting periods. Pain 2008; 139(1): 146-157.

46. Walentynowicz $M$, Bogaerts $K$, Van Diest I, et al. Was it so bad? The role of retrospective memory in symptom reporting. Health Psychol 2015; 34(12): 1184.

47. Fuchs $M$, Bossert $D$ and Stukowski S. Response rate and nonresponse bias-impact of the number of contact attempts on data quality in the European Social Survey. Bull Sociol Methodol 2013; 117: 26-45.

48. Rindfuss RR, Choe MK, Tsuya NO, et al. Do low survey response rates bias results? Evidence from Japan. Demograp Res 2015; 32: 797. 


\section{DuEPublico}

Duisburg-Essen Publications online
DE IS SBEN R G

Offen im Denken

This text is made available via DuEPublico, the institutional repository of the University of Duisburg-Essen. This version may eventually differ from another version distributed by a commercial publisher.

DOI: $\quad 10.1177 / 0269216318818022$

URN: urn:nbn:de:hbz:464-20210505-095415-5

This publication is with permission of the rights owner freely accessible due to an Alliance licence and a national licence (funded by the DFG, German Research Foundation) respectively.

(C) The Author(s) 2018. All rights reserved. 